\title{
Vantagens, dificuldades e reflexos dos dispositivos móveis na educação
}

\author{
Advantages, difficulties and reflexes of mobile \\ devices in education
}

\author{
Felipe Gustavo Vieira de Almeida \\ Instituto Federal do Pará \\ Wellington Blender Palheta Silva \\ Instituto Federal do Pará \\ Caren Vanessa Pinheiro Castro \\ Instituto Federal do Pará \\ Reinaldo Eduardo da Silva Sales \\ Instituto Federal do Pará
}

\begin{abstract}
Resumo: Mesmo com o grande potencial de comunicação que os dispositivos móveis possuem, na educação eles ainda têm sido pouco usados pelos professores. Por isso, investigou-se as vantagens, dificuldades e reflexos destes dispositivos na educação. Participaram da pesquisa 22 alunos do curso de técnico em informática do Instituto Federal do Pará. Utilizou-se a abordagem quanti-qualitativa, de caráter exploratório com a aplicação de questionários em uma atividade em sala de aula, com o uso dos celulares em um jogo construído a partir das métricas da gamificação e conteúdo de uma das disciplinas do curso. O emprego das tecnologias móveis foi apontado como vantajoso para $90 \%$ dos alunos, e a gamificação deixou a aula mais interessante para $95 \%$ da turma. Os dispositivos móveis aliados a gamificação influenciaram positivamente no aprendizado trazendo benefícios para as atividades acadêmicas, como maior interesse, autonomia e criatividade dos estudantes.
\end{abstract}

Palavras-chave: Dispositivos móveis. Gamificação. Vantagens.

\begin{abstract}
Even with the great communication potential that mobile devices have, in education they have still been little used by teachers. Therefore, the advantages, difficulties and reflexes of these devices in education were investigated. Twenty-two students from the IT technician course at the Federal Institute of Pará participated in the research. We used the quantitativequalitative approach, of an exploratory nature with the application of questionnaires in a classroom activity, with the use of cell phones in a game. built from the gamification metrics and content of one of the course subjects. The use of mobile technologies was seen as advantageous for $90 \%$ of students, and gamification made the class more interesting for $95 \%$ of the class. Mobile devices coupled with gamification positively influenced learning, bringing benefits to academic activities, such as greater interest, autonomy and creativity of students.
\end{abstract}

Keywords: Mobile devices. Gamification. Benefits. 
ALMEIDA, Felipe Gustavo Vieira de; SILVA, Wellington Blender Palheta; CASTRO, Caren Vanessa Pinheiro; SALES, Reinaldo

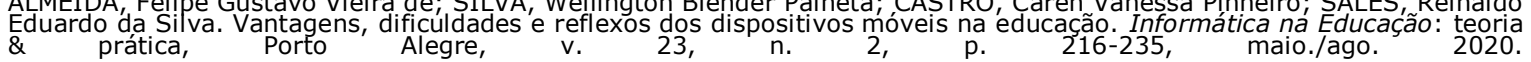

\section{Introdução}

Muito se tem discutido sobre a falta de interesse dos estudantes em relação à aprendizagem e aos conteúdos ministrados pelos professores. Na escola que segue o modelo tradicional, o aprendizado é obtido pela memorização dos conteúdos de forma mecânica com resultados previsíveis. Por outro lado, a sociedade atual demanda por indivíduos proativos e críticos na tomada de decisão. Todavia, essas características não são alcançadas com as metodologias tradicionais de ensino. Elas faziam sentido antes do advento das tecnologias digitais e da internet, quando o acesso à informação vinha exclusivamente pelo professor. Porém, com o avanço dessas tecnologias nas mais diversas camadas da sociedade, os estudantes têm acesso a múltiplas fontes de informação, de muitas formas e em muitos lugares.

Para Moran, Massetto e Behrens (2012), a exploração das multimidias presentes nas Tecnologias Digitais da Informação e Comunicação (TDICs) cria oportunidades de interação e produção de saberes, auxilia na promoção da cultura e ao mesmo tempo, é desenvolvido um processo pessoal que envolve estilo, aptidão e motivação. Para Almeida e Silva (2011), no momento em que essas tecnologias foram trazidas para os espaços pedagógicos pela mão dos estudantes, isto no sentido literal, através dos dispositivos móveis, ou pelo seu modo de pensar e agir, característico da geração digital, fica claro que as tecnologias digitais não podem ser excluídas do processo de ensino.

Entretato, na escola a palavra celular se tornou sinônimo de distração e problema, o acesso à outra fonte de interatividade diante de uma aula chata, é algo mal encarado pelo professor. Assim, nos deparamos com o seguinte problema: de que forma tornar o uso desses aparatos tecnológicos atrativos aos olhos dos professores e coordenadores pedagógicos?

Essa desaprovação do uso das tecnologias no ambiente escolar por parte desses sujeitos se justifica dependendo da forma que os aparelhos são utilizados. Os alunos não contam com a perícia para usar a tecnologia de forma adequada do ponto de vista pedagógico. Na verdade, o uso dos dispositivos móveis no Brasil é educacionalmente subutilizado (IBOPE, 2015), sobretudo, os smartphones. Por isso, é imporante pensar formas de como usar os dispositivos para engajar e catalisar conhecimento entre os alunos.

As tecnologias móveis possibilitam o uso de aplicações de caráter educacional, por meio de recursos como imagem, vídeo, texto, áudio, sensores e conexão sem fio com a internet. Raramente os estudantes têm alguma orientação em como utilizar esses aparatos com viés educacional, desperdiçando dessa forma um rico instrumento. Diante disto, é uma postura difícil da escola conviver tão de perto com as tecnologias e não as aproveitar (ALMEIDA e SILVA, 2011). Por isso é muito importante adequar metodologias, conteúdos e espaços a essas novas demandas. Isto posto, com tantos recursos e disponibilidade que o aparelho oferece, por que não o usar no ambiente educacional? 
Assim, é necessário que gestores, professores e pesquisadores na área de educação busquem novas estratégias e novas perspectivas sobre a forma de educar, tendo em mente o impacto dessas tecnologias na sociedade. $O$ uso de tais tecnologias no meio educacional é um grande passo para mudanças positivas no aprendizado dos estudantes, pois trazem a diversidade para a sala de aula, multimídia, softwares e plataformas que possibilitam a dinamicidade, produtividade e ludicidade nas práticas de ensino.

Neste contexto, o propósito deste trabalho é constatar as vantagens, dificuldades e reflexos do uso dos dispositivos móveis associadas a gamificação na educação. Para tanto, foi realizada uma atividade gamificada por meio de smartphones, com 22 alunos de uma turma de $2^{\circ}$ do ano do curso de informática integrado ao ensino médio e a professora que ministra Programação Orientada a Objetos, no Campus Castanhal do Instituto Federal do Pará (IFPA). Os dados coletados a partir das observações e da aplicação de questionários foram analisados e estão apresentados na seção quatro deste trabalho.

\section{A tecnologia e o processo de ensino aprendizagem}

O aprendizado não acontece somente dentro do ambiente escolar, mas durante toda a vida do indivíduo (OLIVEIRA, 2006). O professor não pode ignorar os conhecimentos pré-adquiridos do aluno. Da mesma forma, é impossível negar a importância e o valor cultural da tecnologia na vida dos estudantes desta geração altamente informatizada. Os impactos da tecnologia provocaram mudança de hábitos, transformações na cultura e a forma como a sociedade interage.

Constata-se uma quebra de paradigmas quanto ao que se espera de um professor. Atribuise ao docente a função de orientar os aprendizes na direção certa. Igualmente, os recursos culturais (fala, escrita e a tecnologia) expandem as capacidades de aprendizado "tornando a sabedoria do passado analisável no presente e passível de aperfeiçoamento no futuro" (VYGOTSKY et al., 1988, p. 26). A tecnologia tem um grande potencial para promover a qualidade da educação, aproximar a escola do universo do aluno e o conhecimento informal ao conhecimento acadêmico.

Com o advento das TDICs, abre-se uma oportunidade indispensável para que esse recurso seja aplicado na escola, já que por seu intermédio se utiliza a internet, e-mails, comunicação virtual e o acesso à informação (MORAN, MASSETTO e BEHRENS, 2012). A internet é o mecanismo que movimenta o mundo. A gigantesca rede mundial de computadores se tornou uma necessidade básica em diversas áreas como economia, cultura, política, produção de bens e serviços, entretenimento e também na educação.

Para Oliveira, Moura e Souza (2015) a internet traz uma abundante diversidade de informações, mídias, softwares, plataformas e aplicações que auxiliam na missão da escola: a aprendizagem. A tecnologia tem um papel importante, como uma catalisadora de saberes, uma 
ponte de conhecimento e aprendizado. Sua enorme popularização foi a principal responsável pelo crescimento e intensificação do uso das TDICs na educação.

Em um contexto educacional, a tecnologia tem um papel importante nas metodologias ativas, pois além de integrar os alunos em seu ambiente tecnológico, traz maior facilidade de acesso à informação, aproximando os ambientes físicos aos digitais (MORAN, 2015). Tendo o professor como um orientador, o aluno pode se beneficiar da internet, buscar a informação certa com intuito pedagógico, dentro dos conteúdos de interesse do docente e da comunidade acadêmica.

A escola precisa buscar novas formas para se enquadrar nos padrões da sociedade, revendo e organizando os currículos, metodologias e espaços, para que os alunos aprendam de forma adequada. Para isso, é necessário filtrar, selecionar e categorizar o que é recebido. O papel do professor, neste cenário, converte-se em auxiliar e direcionar o conteúdo, mediando o aluno a seu objetivo.

\subsection{As metodologias ativas e a gamificação no processo de ensino}

As metodologias ativas permitem ao aluno aprender de forma autônoma e participativa. Segundo Camargo e Daros (2018), elas são um conjunto de atividades organizadas, que tem como essência a prática educativa, no qual os estudantes tornam-se autônomos por meio de estratégias pedagógicas que estimulam a apropriação, a produção do conhecimento e a análise de problemas.

A tecnologia tem um papel importante no uso das metodologias ativas, pois além de integrar os discentes em seu "habitat natural" tecnológico, e trazer maior facilidade de acesso à informação, podem também aproximar os ambientes físicos e digitais (MORAN, 2015). O computador e a internet atraem a atenção dos alunos desta geração tecnológica, desenvolvendo neles habilidades para captar e filtrar a informação que os estudantes de décadas anteriores jamais obteriam com a facilidade vista hoje (OLIVEIRA, MOURA e SOUZA, 2015).

Para Moran (2015), as mais conhecidas metodologias ativas são: ensino híbrido, sala de aula invertida, Aprendizagem Baseada em Problemas (ABP) e a gamificação, alvo deste estudo.

O termo gamificação começou a ser utilizado por volta de 2010 e basicamente, significa utilizar os fundamentos dos jogos em atividades fora do seu contexto. Segundo Kapp (2012, p. 202), a gamificação é "o uso de mecânicas, estéticas e pensamentos dos games para engajar pessoas, motivar a ação, promover a aprendizagem e resolver problemas".

Zichermann e Cunningham (2011, p. 61) definem gamificação como "o processo de raciocínio e mecânica de jogo para engajar os usuários e resolver problemas". São diversas a aplicabilidades da gamificação. É possível gamificar qualquer área do conhecimento, visto que "é a mecânica de um jogo - não o tema - que o tornam divertido".

O conceito já é bastante utilizado nas mais diversas áreas da sociedade, inclusive na educação, em virtude da natureza dos games, sua facilidade de conquistar a atenção do 
jogador e fazê-lo aprender enquanto está entretido. Os jovens de hoje compõem uma geração que cresceu juntamente com a revolução digital e são os que mais utilizam tecnologias, como os games, por exemplo. Para eles, os jogos eletrônicos utilizados como lazer são partes de sua cultura, visto que geram interesse e motivação em sua prática (AZEVEDO, 2012).

Os jogos revelam a oportunidade de tornar os conteúdos mais atrativos, empregando conceitos e recursos dos games. Nas palavras de Moran (2015, p. 29), "os materiais serão mais atraentes, com muitos recursos típicos dos jogos: fases, desafios, competição, colaboração, recompensas".

Os estudantes, especialmente os adolescentes, já se encontram familiarizados com elementos de games, sendo assim, o uso da gamificação torna-se uma estratégia possível e viável para motivar os alunos e potencializar o aprendizado (MORAN, 2015). Somando-se a popularização dos dispositivos móveis, se usufrui da disponibilidade de uma tecnologia que viabiliza a metodologia da gamificação.

Para Silva (2015, p. 20), a "gamificação aplicada à educação traz, além do benefício da motivação dos alunos, uma nova forma de avaliar os participantes do curso, utilizando elementos como: pontuação, nível e ranking". A proposta da gamificação foi pensada para motivar, engajar e influenciar positivamente na mudança do comportamento de um público definido por intermédio da utilização de elementos de jogos, cujo uso possibilita resultados melhores do que os alcançados por métodos tradicionais de ensino.

Se os games são um instrumento para potencializar o aprendizado, como utilizá-los junto com as tecnologias móveis? Para começar a responder essa questão, partimos do pressuposto que todos os alunos e professores tenham acesso aos acessórios móveis. Diante disso, foi necessário este estudo com esses indivíduos para confirmar ou refutar nossas hipóteses.

\subsection{A relação dos dispositivos móveis com a educação}

Grossi e Fernandes (2014) defendem o uso dos dispositivos móveis como um notável instrumento no processo de ensino, quando tomados os devidos cuidados e seu uso orientado por um professor. Tais aparatos se convertem em ótimos instrumentos pedagógicos, que servem para gerar interatividade ao conteúdo, especialmente devido suas diversas funcionalidades e os inúmeros recursos e possibilidades dos dispositivos.

Apesar de muitas possibilidades presentes nos dispositivos móveis, seu uso na maior parte da sociedade (especialmente na escola) não passa de acesso à navegação na internet, redes sociais e aplicativos mensageiros. Existe um grande potencial com aplicativos educacionais que não é bem aproveitado. As possibilidades de conexões no espaço virtual são muitas e estimulam o compartilhamento, a troca de ideias e o acesso a diferentes informações (MARTINS, 2018).

Para Roesler (2008), o uso de dispositivos móveis favorece tanto a compreensão quanto à reorganização dos conteúdos, resultando na associação dos conhecimentos anteriormente absorvidos pelos estudantes. Portanto, mobilidade, conectividade e interatividade são atributos 
intrínsecos dos dispositivos móveis, e a tarefa da escola é encontrar uma forma de como utilizá-los para promover o ensino e a aprendizagem.

O uso de laboratórios com computadores e um projetor, pode parecer um grande avanço, mas na maioria das vezes, na prática não é muito diferente de cadernos e uma lousa com giz. Neste cenário, cabe ao professor refletir nas possibilidades em como usar todo potencial da tecnologia disponível e seus recursos. Então, questiona-se, de que forma o uso das tecnologias móveis pode contribuir para o processo de ensino aprendizagem?

Alguns exemplos das várias aplicabilidades do dispositivo são filmar, tirar fotos, produzir montagens, fazer anotações, gravar o áudio, além de oferecer uma grande variedade de aplicativos, para atender múltiplas necessidades, inclusive, educativas. Todas essas tecnologias foram criadas para facilitar a vida das pessoas, no entanto, se utilizadas sem a orientação necessária, bem como qualquer outro recurso tecnológico, podem empobrecer o ato educativo.

De acordo com a Fundação Getúlio Vargas (2019), o Brasil chegou em 2019 a incrível marca de 420 milhões de dispositivos em uso no país. Há o dobro de aparelhos que pessoas no território nacional. Destacando-se o uso do celular entre todas outras tecnologias, a comunicação móvel gera diversos impactos na sociedade, desde o momento em que o telefone se tornou celular, ele deixou de ser uma ferramenta unicamente para comunicação através da fala, adquirindo novas funcionalidades, sobretudo com o uso dos aplicativos.

Segundo pesquisa do IBOPE$^{1}$ realizada com 2.000 internautas em dezembro de 2015 revela que, em média, os internautas possuem 15 aplicativos instalados nos dispositivos móveis (60\% possuem entre 5 e 20 Apps). Apesar disso, metade dos entrevistados (49\%) usa diariamente menos de cinco Apps e $42 \%$ utilizam entre cinco e dez por dia.

A maioria dos alunos tem um computador em seu bolso, cuja miniaturização dos chips trouxe a possibilidade de acesso a maior rede de informações do mundo na palma da mão (LAIGNIER, 2008). O uso do celular e outras tecnologias da informação se tornaram relevantes e evidentes no cotidiano da sociedade.

Apesar disso, há leis estaduais que vetam o uso dos dispositivos móveis em sala de aula, como é o caso da lei no 7.269, de 2009. A escola precisa aceitar que os celulares fazem parte da vida da maioria esmagadora da sociedade, incluindo os próprios professores, diretores, coordenadores... Porém, apenas a introdução de tecnologia não traz por si só a mudança no processo pedagógico. Há a necessidade de professores qualificados que saibam como orientar os alunos quanto ao uso dos equipamentos (SOARES, 2016). Em pesquisa realizada pelo Centro Regional de Estudos para o Desenvolvimento da Sociedade da Informação (CETIC) verificou-se que em 2016 a presença da tecnologia, em especial a internet, incluída na sala de aula é cativante para os alunos. Esta é apenas uma porta para diversas outras aplicações que podem ser utilizadas como ricas tecnologias no aprendizado, fato que pretendemos demonstrar ao longo deste trabalho.

\footnotetext{
${ }^{1}$ Disponível em: https://www.ibopeinteligencia.com/noticias-e-pesquisas/whatsapp-e-o-aplicativo-maisusado-pelos-internautas-brasileiros/ Acesso em: 30 de março de 2019.
} 
A tecnologia não é só bem vista pelos alunos; os professores também obtiveram proveito no uso dos computadores e da internet, e alcançaram impactos positivos fazendo uso das TDICs em práticas pedagógicas (CETIC, 2016). Negar a importância do aparelho na vida dos estudantes sem tirar o mínimo de proveito e vetar o uso dos celulares na sala de aula, pode significar uma perda de infinitas possibilidades, inviabilizando o aproveitamento de uma grande oportunidade de avanço na educação. Por outro lado, trazer para o centro das discussões tentativas de como se beneficiar do uso do celular e demais tecnologias móveis é um ótimo passo rumo a uma nova educação.

Para Gomes (2014, p. 91) "a introdução de novas tecnologias na sala de aula tem uma longa história de insucesso, mas todos concordarão que o aluno deve ver na escola um espaço onde lhe é aberto o futuro e nunca uma iniciação dolorosa e de utilidade duvidosa".

Discutir o uso dos dispositivos móveis como tecnologia educacional, tem reflexos diretos na comunidade acadêmica. Assim, as escolas, docentes e gestores na área educacional podem usar a tecnologia como recurso didático e pedagógico, usando do aparelho para criar projetos e atividades. E é isto que este se trabalho se propõe nas próximas seções.

\section{Materiais e métodos}

A pesquisa de campo que foi desenvolvida se classifica como exploratória em virtude da natureza da investigação: o uso dos dispositivos móveis associados a gamificação como instrumento pedagógico. Dessa forma, o propósito era evidenciar as vantagens, dificuldades e reflexos destes dispositivos no âmbito educacional.

A abordagem usada para a análise dos dados foi à quanti-qualitativa. A qualitativa explicase por se tratar de um assunto com muitas opiniões dos sujeitos da pesquisa; já a quantitativa se justifica porque procurou-se medir numericamente os dados de como se apresenta o objeto de estudo.

Johnson et al. (2007) define a abordagem mista como o tipo de investigação em que se combina os princípios quanti-qualitativos, cujo objetivo é perceber as opiniões e aferir comprovação numérica dos dados coletados.

\subsection{Local da pesquisa}

A pesquisa ocorreu no Campus Castanhal do Instituto Federal do Pará. Localizado na Região Metropolitana de Belém, é o segundo maior do IFPA, sendo um dos mais antigos campi. Originalmente foi criado no Distrito do Outeiro², se instalando na cidade de Castanhal em 1972, no formato de Escola Agrotécnica, que oferecia o curso de ensino médio junto ao de Agropecuária. Com a criação dos Institutos Federais em dezembro de 2008, passou a ser chamado de campus Castanhal do IFPA (PASSOS e SALES, 2019).

\footnotetext{
${ }^{2}$ Município de Belém.
} 
O campus é especializado na oferta de educação profissional de ensino básico, técnico e tecnológico. Nele são ofertados um curso de mestrado (Desenvolvimento Rural), cinco cursos de graduação (Agronomia, Engenharia de Pesca, Aquicultura, Engenharia de Alimentos e Licenciatura em Informática), dois cursos técnicos integrados ao ensino médio (Agropecuária e Informática) e cinco cursos técnicos subsequentes (Meio Ambiente, Agropecuária, Agroindústria, Floresta e Rede de Computadores), com mais de 1.500 estudantes. Em sua maior parte, os cursos existentes no campus seguem dois perfis profissionais: um Agropecuário e outro ligado a Tecnologias da Informação (TI).

\subsection{Instrumentos de coleta, sujeitos da pesquisa e materiais utilizados}

Os dados foram coletados através de observação e da aplicação de um questionário com três perguntas que versavam sobre as vantagens, dificuldades e reflexos do uso dos dispositivos móveis na educação. As respostas obtidas por meio desses instrumentos encontram-se organizadas e analisadas na quarta seção deste artigo.

Participaram da pesquisa 22 alunos (dos quais, um é deficiente visual) da turma do $2^{\circ}$ ano do curso técnico integrado em informática e com a professora de Programação Orientada a Objetos (POO) que ministra suas aulas nesta turma, perfazendo um total de 23 sujeitos. Desse total de estudantes 15 são homens e 7 são mulheres. Suas idades variavam entre 14 e 18 anos. Seus nomes foram mantidos no anonimato, além disso, a professora assinou o termo de consentimento livre e esclarecido (TCLE).

Com esses indivíduos realizou-se uma atividade gamificada por meio de um aplicativo nos smartphones dos estudantes. A procura pelos programas educacionais foi realizada via serviço de distribuição digital da Google, a plataforma Google Play, além de sites especializados em uso da tecnologia como mediação pedagógica. Tendo como base os critérios de facilidade na aplicação, possibilidade do professor fazer seu próprio conteúdo, interface agradável, gratuidade e recursos extras, o aplicativo escolhido foi o Metaverse. Desenvolvido pela empresa GoMeta, é um poderoso instrumento com enfoque em realidade aumentada, na qual professores e alunos podem criar várias experiências. O software permite aos docentes criarem divertidos jogos de perguntas e respostas, avaliações em forma de formulários e práticas de realidade aumentada, semelhante ao famoso jogo "Pokemon GO".

Para a criação do conteúdo, primeiramente, é preciso acessar a plataforma web do aplicativo, estúdio Metaverse, onde é possível a criação de qualquer material independente da disciplina, onde o único limite é a criatividade. A ferramenta possibilita variados usos dos recursos dos dispositivos móveis, câmera com realidade aumentada e selfies; serviço de localização pelo Sistema de Posicionamento Global (GPS) para eventos em determinados locais; uso de áudio e vídeo; uma extensa biblioteca de personagens e imagens para criação do conteúdo lúdico/gamificado; além de tudo, os desenvolvedores disponibilizam em seu canal do Youtube diversos tutorias sobre os procedimentos adotados. No fim do desenvolvimento é disponibilizada a atividade para os aparelhos móveis via link ou código QR e durante o 
desenvolvimento é possível acompanhar o desempenho de cada participante por meio de uma tabela de classificação.

É possível construir vários tipos de experiências interativas de aprendizado para as aulas, independente da faixa etária, embora os jovens são os mais familiarizados com os jogos. 0 ponto forte da plataforma é que qualquer pessoa pode criar seus próprios jogos ou experiências, sem necessidade de conhecimento técnico da programação, as aplicações são construídas através da conexão dos elementos do jogo em uma ordem lógica.

Na figura 01 são apresentados os principais elementos na construção de uma experiência na plataforma de desenvolvimento: (1) Blocos usados para ações e elementos lógicos (2) Cenas de interface visual, podem conter textos, personagens e botões; e (3) Painel de configurações.

Figura 1: Captura de Tela da Plataforma Metaverse Estúdio

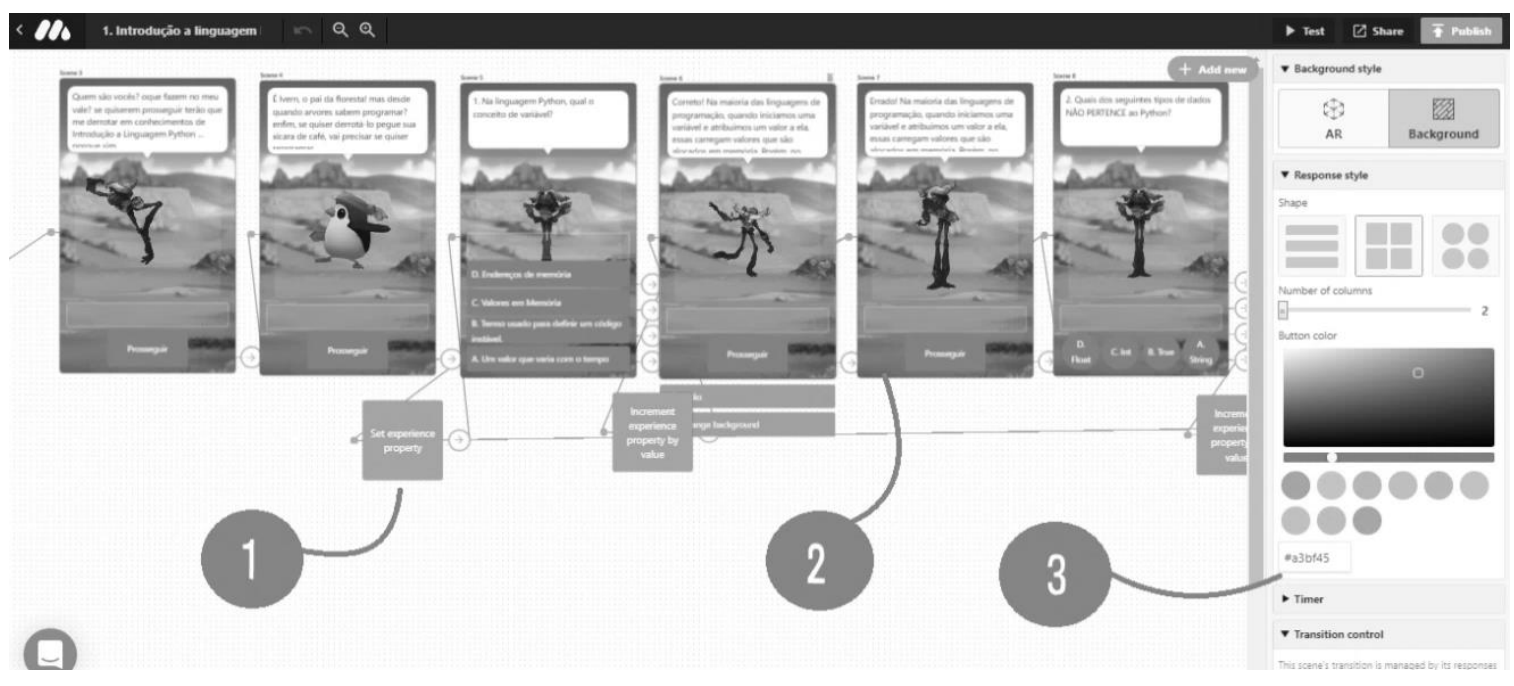

Fonte: Os Autores

Definido o aplicativo que iria ser usado, o próximo passo foi criar, com a ajuda da professora de POO, uma atividade gamificada utilizando o aplicativo Metaverse.

\subsection{Elaboração do jogo}

Os conteúdos presentes no game faziam parte da ementa da disciplina POO. Na produção do jogo foram empregados modelos de personagens, áudios e imagens ilustrativas como elementos lúdicos. Também foram usados os conceitos de gamificação na construção, com um roteiro e personagens cujo objetivo era derrotar um chefão baseado na pontuação do aluno respondendo a um quiz com perguntas dos conteúdos da disciplina. Na medida em que novos conteúdos eram estudados pelos alunos, um novo chefão com maior dificuldade era apresentado. $\mathrm{O}$ jogo foi elaborado tendo em mente que a turma continha um aluno deficiente visual, desta forma, a atividade foi testada juntamente com aplicativos leitores de tela, por exemplo, o talkback. 
Para garantir que o game fosse acessível para a pessoa com deficiência, fez-se uma consulta ao Núcleo de Atendimento às Pessoas com Necessidades Especificas (NAPNE) do campus com uma profissional da área da acessibilidade, no qual o aplicativo foi apresentado e aprovado pela mesma. No resultado final, com ajuda do leitor de tela, o jogo poderia ser usado com simples gestos na tela, um gesto para prosseguir, e dois toques para selecionar uma alternativa, assim, o conteúdo era falado por meio do áudio.

\subsection{Aplicação da atividade}

Desenvolvido e testado o jogo, ele foi realizado com o uso dos dispositivos móveis. Começou-se explicando quais os conteúdos e exercícios seriam abordados na atividade. Em seguida, pediu aos estudantes que fizessem o download do Metaverse. Após isso, sucedeu a apresentação do projeto, do que se tratava, qual sua funcionalidade e onde pode ser utilizado. Alguns alunos perguntaram se havia outras possibilidades de uso desse aplicativo, além do caráter educacional. Foi dito que o Metaverse também é usado por empresas para exibir portfólio de produtos, utilizando a realidade aumentada com objetos 3D, bem como em eventos para fazer demonstrações de locais. Logo depois, foi distribuído o link de acesso ao game. Os alunos estavam bastante empolgados com a atividade, especialmente os meninos. A maioria deles conseguiu finalizar a atividade e derrotar o chefão. No fim do game os jogadores podiam tirar uma foto para registrar o momento, onde ficaria postada em um mural no aplicativo. Ao todo, a atividade durou cerca de 20 minutos.

Decorrido o tempo dessa atividade, foram entregues os questionários aos discentes e a docente da respectiva prática, relatando suas experiências do período, as vantagens, assim como problemas enfrentados e cuidados necessários para um melhor resultado. Esses dados foram analisados e constam na próxima seção deste trabalho.

\section{Resultados da atividade gamificada com os dispositivos móveis}

Nesta seção serão apresentados e analisados os resultados da pesquisa, demonstrando a percepção dos alunos e da professora da turma em relação à experiência vivenciada. O foco é constatar se essa metodologia trouxe benefícios, se alcançou as expectativas, quais suas limitações e quais foram os reflexos da introdução dos dispositivos móveis e da gamificação nas aulas. Os dados da pesquisa foram interpretados com base na teoria pré-estabelecida que norteia o problema do trabalho, fazendo um paralelo entre a teoria e a realidade observada.

As respostas abstraídas com os questionários e as observações foram agrupadas em três subseções: a) vantagens no processo de ensino aprendizagem; b) dificuldades encontradas; e c) reflexos da introdução da gamificação nas aulas.

\subsection{Vantagens no processo de ensino aprendizagem}


Com base na experiência desenvolvida, nas observações e nas respostas dos questionários, verificou-se que a atividade trouxe benefícios para o processo de aprendizado dos estudantes. Segundo as respostas dos questionários, $90 \%$ dos alunos (conforme o gráfico 1) concordam, seja totalmente ou parcialmente, que o uso dos dispositivos móveis traz vantagem pedagógica, sustentando assim, a ideia de melhoria advinda com os aparelhos em sala de aula. A professora da turma afirmou que a atividade trouxe dinamicidade e interatividade na aula, mesmo com dificuldades encontradas. Em suas palavras ela relata que a atividade foi positiva "...apesar da dificuldade de acesso à internet e o fato de que alguns poucos alunos não tinham celular, percebe-se que foi uma prática inovadora dentro da disciplina, dinâmica e interativa".

De acordo com Martins (2018), o uso da tecnologia, de modo geral, e dos dispositivos móveis, em particular, possibilita aos professores e alunos mudanças significativas nos seus respectivos papéis no contexto escolar, demandando cada vez mais indivíduos ativos no processo de ensino e aprendizagem.

\section{Gráfico 1: Opinião dos alunos sobre as vantagens do uso do celular}

O uso dos celulares nas atividades da disciplina trouxe vantagem no processo de ensino aprendizagem?

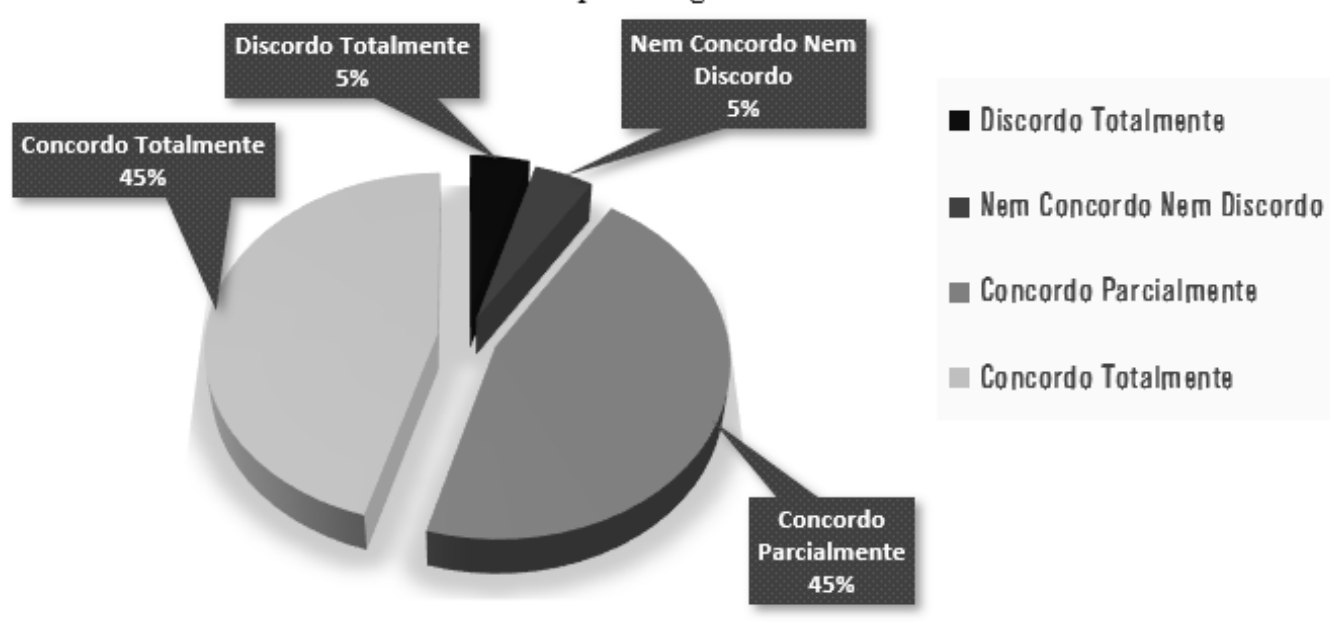

Fonte: Os Autores

O processo de aprender, de acordo com Oliveira (2006, p. 61) é "o processo pelo qual o sujeito adquire informações, habilidades, atitudes e valores, a partir do seu contato com a realidade, o meio ambiente e as outras pessoas". Com base neste entendimento, e comparando com as observações feita no momento da experiência, a presença da tecnologia móvel catalisou esse processo, graças a natureza lúdica e divertida do jogo, somado a multimídia disponível nos smartphones e os desafios provenientes da gamificação.

Destacando a principal contribuição dos dispositivos móveis, a multimidia, os estudantes concluiriam a atividade enquanto se divertiam ouvindo as pequenas histórias engraçadas dos personagens, assimilando a história e os personagens do jogo com os conteúdos da disciplina, e compartilhando seu conhecimento com os colegas. Conteúdos estes que poderiam ser de 
uma prova/exame, mas em um contexto onde os aprendizes se sentiam mais à vontade, mais engajados e interessados a participar, o que facilitou significativamente o aprendizado.

Percebem-se nas respostas dos envolvidos que o emprego das plataformas móveis enriqueceu o aprendizado durante a aula. Martins (2018) aponta que os professores que buscarem transformar os dispositivos móveis em tecnologias educacionais certamente terão um leque de novas possibilidades e metodologias a sua disposição.

A UNESCO (2013) criou um guia com treze motivos e dez recomendações orientando governos e escolas para fomentar o uso dessas tecnologias no contexto educacional, dentre os quais foram observados durante a pesquisa: a) auxiliar estudantes com deficiências; e b) criar uma ponte entre a aprendizagem formal e a não formal ${ }^{3}$.

Os aparelhos promoveram a inclusão graças à integração das tecnologias presentes no dispositivo como a de texto por meio da fala. Por exemplo, os smartphones podem melhorar significativamente o aprendizado desses estudantes, como foi com um aluno deficiente visual. No decorrer da atividade foram incorporados elementos do jogo tendo em mente sua compatibilidade com o leitor de tela talkback. Assim, o deficiente visual pôde ter acesso às questões e respondê-las. A utilização apropriada das características desses dispositivos e sua capacidade multimídia permitem as pessoas com necessidades especiais cumprir tarefas seja dentro ou fora da escola, ampliando suas capacidades e aumentando significativamente suas possibilidades de aprendizado.

O uso dos dispositivos móveis permitiu trazer para a sala de aula o universo do aluno, como no exemplo da pesquisa, muitos se interessaram pela atividade, pois os personagens eram de um jogo eletrônico, do qual eles estavam familiarizados, desse modo, completaram a atividade com entusiasmo.

É de fundamental importância que as instituições de ensino busquem metodologias que visam à independência do aluno, para tomar decisões fundamentadas no conhecimento compartilhado pelo professor e não apenas memorize esse conhecimento. Para tanto, as tecnologias móveis cumprem um papel importante fazendo com que os estudantes sejam sujeitos de seu aprendizado. Como no caso da aplicação, um jogo é um ótimo exemplo para aproximar o cotidiano do estudante ao conhecimento acadêmico. O desafio somado aos elementos lúdicos presentes na atividade chamou sua atenção dos alunos que entram na competição. No decorrer da atividade, eles usaram seus conhecimentos sobre a disciplina para responder os problemas, com funções e códigos nos mais diversos cenários e possibilidades.

Em relação aos cuidados necessários para que traga benefícios, a UNESCO (2013) recomenda que haja capacitação de professores sobre como fazer avançar a aprendizagem por meio de tecnologias móveis e que se aperfeiçoem conteúdos educacionais para seu uso por meio das TDICs.

Os professores precisam receber formação apropriada para incorporar as tecnologias móveis com sucesso. É necessário que as escolas os estimulem como também forneçam oportunidades

3 Para conhecer as demais recomendações apresentadas pelo Guia da UNESCO, basta acessar http://www.bibl.ita.br/UNESCO-Diretrizes.pdf. 
para a construção de estratégias e experimentação do uso dessas tecnologias. De fato, é muito importante um melhor investimento na formação docente quanto ao uso dessas tecnologias, do que o investimento na própria tecnologia. Ainda segundo a UNESCO (2013), sem orientação e capacitação, os professores na maioria do tempo utilizam a tecnologia para "fazer coisas velhas de formas novas", o oposto de transformar e melhorar abordagens de ensino.

É importante considerar que a professora da classe participou do processo de desenvolvimento do jogo, para garantir que as perguntas e respostas estavam conforme a disciplina, bem como o nível de dificuldade. Ela também permitiu o uso dos dispositivos pelos alunos, somente durante a atividade. As decisões da docente apontam conhecimento sobre a utilização das tecnologias móveis em um contexto educacional e sensibilidade quanto a possíveis empecilhos.

O sucesso do uso de qualquer tecnologia com viés acadêmico depende da capacidade dos professores para aumentar as vantagens educacionais nesses dispositivos. Com os aparelhos móveis não é diferente, sem um professor capacitado para orientar o aluno, a tecnologia pode até atrapalhar no processo de ensino. Também é importante considerar que boa parte dos conteúdos educacionais não se apropria integralmente das propriedades que os aparelhos móveis oferecem.

No exemplo da pesquisa, o jogo poderia ser criado como atividade extraclasse, mas para isso seria necessário todo um processo de preparação, orientação e acompanhamento. De todo modo, é preciso estimular o desenvolvimento de plataformas que permitam que docentes criem ou adaptem conteúdos para aparelhos móveis, como o exemplo do aplicativo Metaverse.

Especialmente quanto às opções de acessibilidade, os atuais padrões dos smartphones trazem algumas dificuldades para pessoas com deficiência ao manuseá-los, a exemplo disso são: a falta de um teclado físico, tamanho reduzido da tela e baixa autonomia de bateria. É essencial durante a elaboração de qualquer conteúdo nos dispositivos móveis a realização de atividades que já apresentem sua própria configuração de acessibilidade, ou no mínimo assegurar sua compatibilidade com aplicativos já disponíveis, para garantir que a atividade desenvolvida seja acessível.

\subsection{Dificuldades encontradas}

Foi verificado, tanto na observação quanto por meio dos questionários, que a maior dificuldade para a realização da atividade gamificada foi o acesso instável da internet no campus. De acordo com as respostas obtidas, 63\% dos alunos, conforme o gráfico 2, concordam, seja totalmente ou parcialmente, que o campus precisa de mudanças e/ou melhoria para que o uso dos aparelhos móveis possa funcionar de forma eficiente como uma estratégia de ensino. 


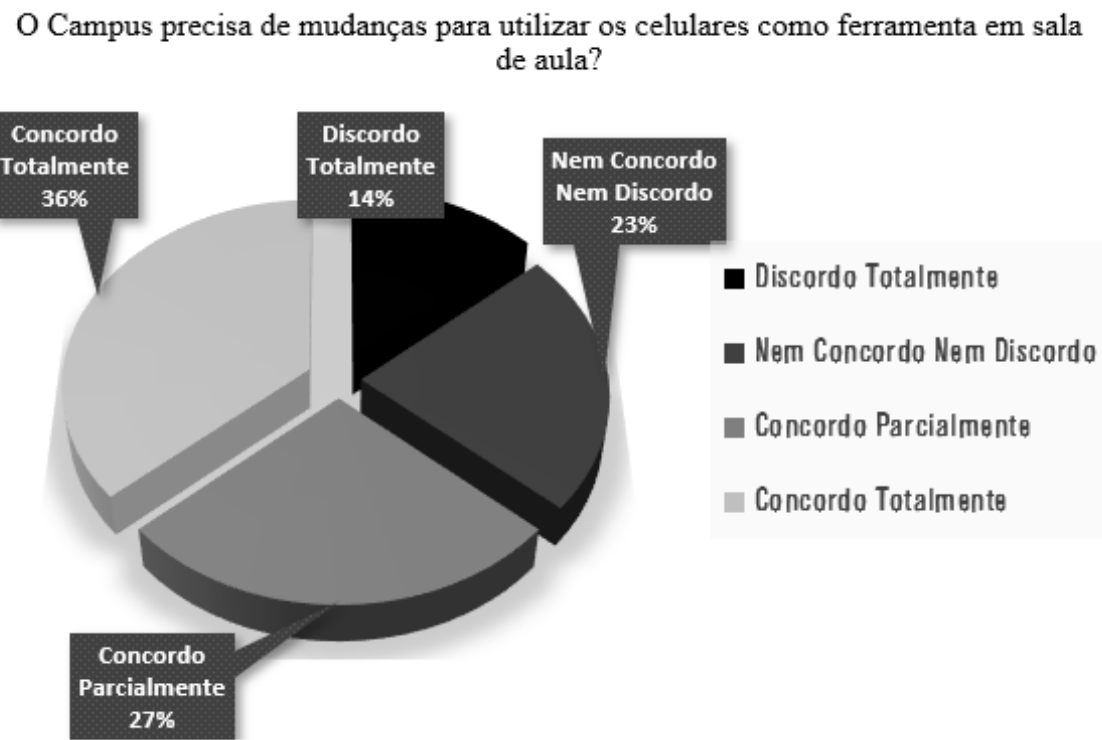

Fonte: Os Autores

Gusmão (2016) aponta que as escolas precisam estar preparadas para lidar com as tecnologias, sobretudo com as digitais em suas atividades. Todavia, o que se observa no contexto brasileiro é bem diferente, uma vez que $95 \%$ das escolas públicas possui computador com algum tipo de acesso, mas são subaproveitados. A disponibilidade de conexão sem fio, incluindo as redes wi-fi, são precárias, não contribuindo para o efetivo acesso à rede. Instabilidade de sinal e a perda de velocidade são os principais problemas encontrados, fato semelhante ao ocorrido durante a realização da pesquisa, que afetou indiretamente o aprendizado, pois prejudicou a prática pedagógica.

É evidente que existem problemas no processo de ensino que extrapolam os limites da tecnologia. Fatores cognitivos, culturais, sócioeconomicos, psico-pedagógicos entre outros, também interferem no aprendizado dos estudantes. Um paralelo bastante claro foi observado durante a pandemia do Corona Vírus ${ }^{4}$, na qual as instituições de ensino, em todos os níveis da educação, disponibilizaram aulas a distância. Entretanto, na prática, nem todos os alunos tiveram acesso a essas aulas, uma vez que nem todos podiam contar com computadores, smartphones ou acesso a internet, revelando desta forma um problema de caráter sócioeconomico e cultural.

Em determinado momento da aula, os alunos precisaram sair da sala para conseguir uma conexão satisfatória para realizar a atividade, pois muitos elementos do jogo (personagens, imagens, e arquivos de áudio e texto) demoravam para serem baixados nos smartphones, isso prejudicou a execução da prática, especialmente a experiência do aluno deficiente visual.

Ainda sobre melhorias no campus, muitos dos discentes indicaram mudanças além da qualidade na conexão sem fio, como capacitação dos professores. Segundo trechos abstraídos

\footnotetext{
${ }^{4}$ Pandemia mundial ocorrida a partir de janeiro de 2020 causada por um vírus que compromete a saúde respiratória da pessoa. Na ocasião da pesquisa, ainda não existia cura para essa doença, sendo recomendada por todos os órgãos de saúde o distanciamento social para evitar que ela se proliferasse. Por isso todas as aulas foram suspensas.
} 
de um questionário é preciso "preparação por parte dos professores", e "responsabilidade em relação aos alunos e mais compromisso e organização em parte dos professores". Como já discutido, a capacitação de professores é essencial para o uso das TDICs no meio educacional.

Alguns alunos apresentaram outras formas de utilização dos celulares na disciplina como "nas resoluções de exercícios e atividades e no reforçamento de conteúdos" e na "utilização de sites ou jogos que possam deixar a aula mais interessante para os alunos". Nota-se que a classe, assim como muitos outros estudantes na mesma faixa etária, já estão familiarizados com as capacidades dessa tecnologia, e propõem a utilização dos vários usos destes dispositivos. Para eles é ideal "utilizar o celular como uma ferramenta para tornar a aula mais lúdica".

De acordo com as diretrizes da UNESCO (2013) para potencializar a aprendizagem através de dispositivos móveis, recomenda-se a ampliação e melhoria nas opções de conectividade, assegurando também a equidade e o aumento na conscientização sobre a aprendizagem móvel por meio de liderança e diálogo. O uso dos aparatos móveis depende de uma boa e confiável conectividade com a internet, pois o acesso à rede é o meio mais prático e rápido para o compartilhamento de conteúdo. No exemplo da pesquisa, com acesso a um link, ou na leitura de um único código QR, os alunos tinham acesso a todas as questões na forma do jogo, apesar dos contratempos da rede wi-fi instável.

À medida que o acesso à informação se torna cada vez mais relevante e mais relacionado com o desenvolvimento econômico e social, é fundamental ampliar a infraestrutura tecnológica, para garantir não apenas a qualidade, mas também a equidade de acesso à conectividade móvel e à informação, sobretudo no meio educacional. Um estudante que não tem a possibilidade de acesso à internet, seja por razões econômicas ou geográficas, tem negada a obtenção a uma vasta gama de oportunidades, aprendizagem, conteúdos e metodologias (ALMEIDA e SILVA, 2011). É necessário examinar a infraestrutura de TDICs nas escolas, para dar suporte à aprendizagem móvel.

Muitas pessoas percebem o uso dos dispositivos móveis somente como formas de entretenimento, não como portais de educação. Como consequência, essas tecnologias são deixadas de lado, e vistas como sinônimo de distração ou perturbação no contexto escolar, e sua inserção traz apenas desvantagens para o processo educacional. Entretanto, essas opiniões estão mudando, em grande parte graças aos avanços tecnológicos nos dispositivos, mesmos nos modelos mais acessíveis e populares, e a novas estratégias para sua utilização com viés pedagógico. Muitos professores e pesquisadores da área da educação já relatam os benefícios dessas tecnologias e promovem ações para seu emprego no meio acadêmico das mais diversas formas, como é o caso da professora pesquisada que defendeu seu uso, desde que se tomem os cuidados necessários.

\subsection{Reflexos da introdução da gamificação nas aulas}


Os dados da pesquisa indicaram que para 95\% dos estudantes (gráfico 3) o uso da gamificação gerou interesse, seja concordando parcial ou totalmente, deixando a aula mais atrativa, além de trazer a diversão associada ao aprendizado.

Gráfico 3: Opinião dos alunos sobre a gamificação

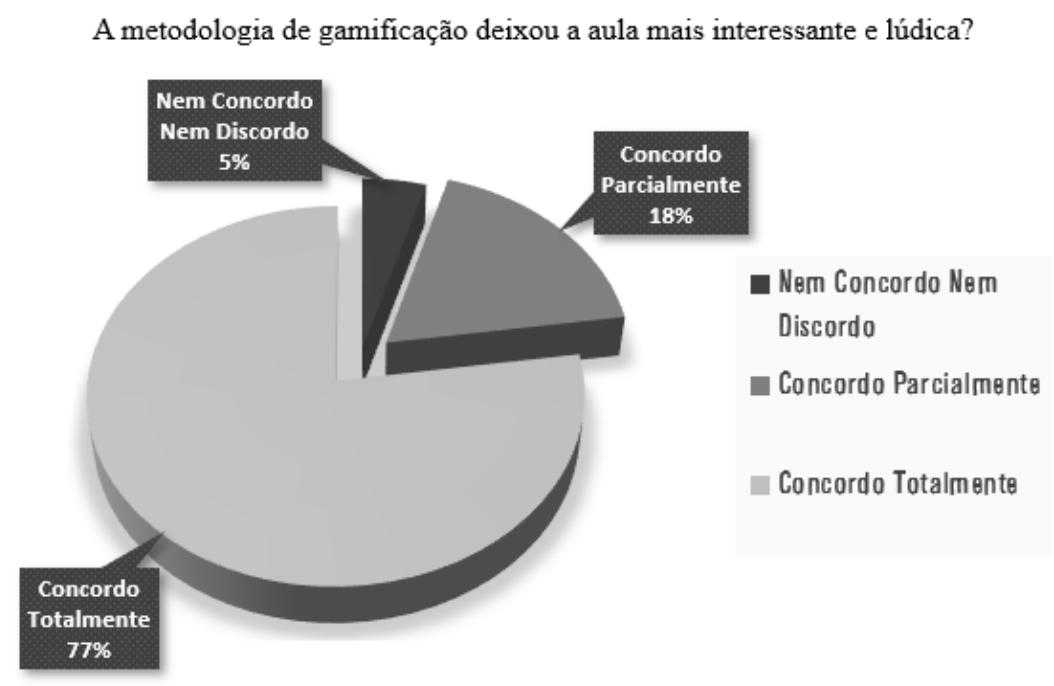

Fonte: Os Autores

Para Kapp (2012), a gamificação utiliza as mecânicas, elementos estéticos e pensamentos dos games para engajar pessoas, motivá-las a ação, promover a aprendizagem e resolver problemas, uma vez que um dos grandes desafios da educação contemporânea é prender a atenção dos alunos. Esta metodologia traz resultados benéficos, especialmente em atividades extraclasse, quando Ihes é solicitado exercícios, atividades ou leituras pelos professores.

Segundo a professora da turma, esta metodologia incentivou a participação dos alunos, uma vez que tinham o interesse em concluir o jogo. Os estudantes precisam experimentar novas formas de mostrar sua iniciativa, para que se tornem mais criativos, uma característica relevante no aprendizado. Se o intuito é formar pessoas proativas, autônomas, sujeitos de sua própria aprendizagem, é importante "adotar metodologias em que os alunos se envolvam em atividades cada vez mais complexas, em que tenham que tomar decisões e avaliar os resultados, com apoio de materiais relevantes" (MORAN, 2015, p. 26).

Como visto na pesquisa, o exemplo da gamificação contribuiu para despertar o interesse dos alunos, aumentar a participação, instigar a criatividade e promover o diálogo para a resolução de problemas. Observou-se que a maioria dos alunos concorda que a proposta do jogo tornou os conteúdos da disciplina mais interessantes. De fato, no momento da experiência, um número significativo se mostrou bastante empolgada com a atividade, isso porque se tratava de um game.

Zichermann e Cunningham (2011) apresentam as razões pelas quais as pessoas são motivadas a jogar os games, separando os motivos em quatro categorias:

- Pela Maestria: Onde o jogador está tentando ganhar algum tipo de competição; 
- Para Desestressar: Cenário em que o jogo muda a forma que o jogador se sente;

- Para se Divertir: Onde o jogador está focado em descobrir o jogo e seus sistemas;

- Para Socializar: Quando o jogador se empenha com a companhia de outros jogadores.

Apesar da possibilidade de explorar todas estas categorias, em um contexto de aprendizagem, maestria, diversão e socialização são as mais evidentes. Foi observado durante a experiência que os discentes se uniram em grupos, para ajudar seus amigos a concluírem a atividade, compartilhando seus conhecimentos por meio do trabalho em equipe. Por outro lado, alguns competiam entre si para finalizar a atividade antes do previsto. Importante mencionar que nada disso foi solicitado, foram os alunos quem preferiram essa organização.

Zichermann e Cunningham (2011) explicam, ao focar no prazer, recompensas e tempo, os jogos são poderosas estratégias para motivação, sendo capazes de prender a atenção das pessoas e fazê-las tomar ação voluntariamente, sendo o desejo de muitos professores produzir aulas com essas características.

Ao finalizar o jogo, os alunos podiam fotografar uma selfie que ficaria gravada em um mural no fim da aplicação para que os demais participantes pudessem visualizá-la. Este é um passo essencial para garantir que os estudantes possam repetir atividades similares ou atividades futuras com a mesma dinâmica. Seu propósito é a divulgação dos méritos alcançados, concedendo aos alunos o reconhecimento e a sensação de missão cumprida.

\section{Considerações finais}

A pesquisa nos permitiu considerar que os dispositivos móveis aliados a metodologia da gamificação têm um grande potencial para melhorar o aprendizado, especialmente entre adolescentes e jovens, resultado do lúdico e da capacidade dos jogos em prender a atenção. 0 produto da junção de todos esses elementos aplicados a uma disciplina e seus conteúdos é um aprendizado divertido e engajador.

A experiencia que foi desenvolvida associando-se a gamificação com o uso dos dispositivos móveis contribuiu para o processo de construção do conhecimento dos estudantes e ainda possibilitou a professora pensar uma nova estratégia de ensino motivadora e contextualizada. Por isso, este processo trouxe resultados benéficos para o ensino, de modo geral, e para estudantes e a professora, em particular.

O uso dos smartphones trouxe vantagens no processo de ensino aprendizagem, pois promoveu a inclusão educacional, bem como aproximou o universo dos estudantes com os conteúdos da disciplina, através das possibilidades das tecnologias móveis. No entanto, é necessário melhorar a estrutura física para o uso integral dessa tecnologia, em especial o acesso à internet sem fio. Da mesma forma, o preparo por parte dos professores é imprescindível para o emprego dos aparatos móveis em espaços acadêmicos. Também foi 
observado na pesquisa que a gamificação despertou interesse, participação, criatividade e o diálogo dos alunos para a resolução das atividades.

As principais dificuldades encontradas na execução do trabalho foram combinar métricas de inclusão com os elementos do jogo, a busca dos elementos lúdicos ideais no desenvolvimento da aplicação e a falta de uma conexão sem fio com a internet satisfatória no momento da atividade.

Para trabalhos futuros, sugere-se o uso de outras plataformas móveis com o foco em gamificação, em especial, o classcraft, que mostrou recursos bastante promissores. Também é pertinente o estudo feito em um intervalo maior de tempo, com o acompanhamento e emprego das tecnologias em um semestre inteiro. Da mesma forma, é relevante estudar o uso das tecnologias com o foco nas atividades extraclasse. Isto não nos foi possível fazer, mas as propostas estão dadas. Em síntese, as tecnologias promovem um aprendizado significativo se utilizadas com método e as ferramentas necessárias para sua execução.

\section{Referências}

ALMEIDA, Maria Elizabeth B; SILVA, Maria da Graça Moreira. Currículo, Tecnologia e Cultura Digital: Espaços e Tempos de Web Currículo. Revista e-curriculum, São Paulo, v. 7, ed. 1, 2011. Disponível em: https://revistas.pucsp.br/index.php/curriculum/article/viewFile/5676/4002. Acesso em: 2 abr. 2020.

ASSEMBLEIA LEGISLATIVA DO ESTADO DO PARÁ. Lei no 7269, de 6 de maio de 2009. Dispõe sobre a proibição do uso de telefone celular. 6 maio 2009. Disponível em: http://www.ioepa.com.br/pages/2009/05/08/2009.05.08.DOE_5.pdf. Acesso em: 15 jan. 2020. AZEVEDO, Victor de Abreu. Jogos eletrônicos e educação: construindo um roteiro para a sua análise pedagógica. Renote, UFRGS, Porto Alegre. V. 10 n 3, 2012.

CAMARGO, Fausto; DAROS, Thuinie Medeiros Vilela. A sala de aula inovadora: estratégias pedagógicas para o aprendizado ativo. Porto Alegre: Penso, 2018.

CETIC. Pesquisa sobre o uso das Tecnologias de Informação e Comunicação nas escolas brasileiras, 2016. Disponível em: https://cetic.br/tics/educacao/2016/alunos/F6/. Acesso em: 3 de outubro de 2019.

FUNDAÇÃo GETÚLIO VARGAS. Tecnologia da Informação. 30a Edição de Pesquisa Anual do Uso de TI 2019, 25 abr. 2019. Disponível em: https://eaesp.fgv.br/sites/eaesp.fgv.br/files/pesti2019fgvciappt_2019.pdf. Acesso em: 5 maio 2019.

GOMES, José Ferreira. A tecnologia na sala de aula. In: VIEIRA, Fátima; RESTIVO, Maria Teresa. Novas tecnologias e educação: ensinar a aprender/aprender a ensinar. Biblioteca Digital da Faculdade de Letras da Universidade do Porto, 2014. E-book.

GROSSI, Márcia Gorett Ribeiro; FERNANDES, Letícia Carvalho Belchior Emerick. Educação e tecnologia: O telefone celular como recurso de aprendizagem. Eccos, São Paulo, ed. 35, p. 47-65, 2014. Disponível em: https://www.redalyc.org/pdf/715/71535318003.pdf. Acesso em: 15 jan. 2020. 
GUSMÃO, Fábio Alexandre Ferreira. Considerações preliminares sobre a associação entre as tecnologias da informação e comunicação e a educação escolar no Brasil. $9^{\circ}$ Encontro internacional de formação de professores, Sergipe, n. 9, p. 1-12, 16 maio 2016. Disponível em: https://eventos.set.edu.br/index.php/enfope/article/view/2037/692. Acesso em: 24 mar. 2020.

IBOPE - Instituto Brasileiro de Opinião e Estatística. WhatsApp é o aplicativo mais usado pelos internautas brasileiros. 15 de dezembro de 2015. Disponível em: https://www.ibopeinteligencia.com/noticias-epesquisas/whatsapp-e-o-aplicativo-mais-usado-pelos-internautas-brasileiros/. Acesso em: 30 jun. 2018.

JOHNSON, R. Burke; et al. Toward a definition of mixed method research. Journal of Mixed Methods Research, v.1, n.2, p. 112-133, 2007.

KAPP, Karl. The Gamification of Learning and Instruction: Game-based Methods and Strategies for Training and Education. São Francisco. Pfeiffer, 2012.

LAIGNIER, Pablo. Breve história dos computadores e do ciberespaço: uma abordagem conceitual. $6^{\circ}$ Encontro Nacional da Rede Alfredo de Carvalho, Niterói/RJ, n. 6, p. 1-15, 13 maio 2008. Disponível em: http://www.ufrgs.br/alcar/encontros-nacionais-1/encontros-nacionais/6o-encontro-2008-1/Breve historia dos computadores e do ciberespaco.pdf. Acesso em: 15 jan. 2020.

MARTINS, José Vorlei Guimarães et al. O uso de dispositivos móveis na sala de aula: pedagogia de projetos e tecnologias móveis na Educação Superior. Revista IberoAmericana de Estudos em Educação, Araraquara, v. 13, n. esp1, p. 506-526, maio 2018.

MORAN, José Manuel, MASSETTO, Marcos T., BEHRENS Marilda Aparecida. Novas tecnologias e mediações pedagógicas. Campinas, SP. Papirus, 2012.

MORAN, José. Mudando a educação com metodologias ativas. [Coleção Mídias Contemporâneas. Convergências Midiáticas, Educação e Cidadania, v. II, p. 15-33, 2015. Disponível em: http://www2.eca.usp.br/moran/wp-content/uploads/2013/12/mudando_moran.pdf. Acesso em: 3 dez. 2019.

OLIVEIRA, Cláudio; MOURA, Samuel Pedrosa; SOUZA, Edinaldo Ribeiro. Tic's na educação: a utilização das tecnologias da informação e comunicação na aprendizagem do aluno. Revista Eletrônica do Curso de Pedagogia da PUC Minas, Belo Horizonte, p. 75-95, 1 jan. 2015. E-book.

OLIVEIRA, Marta Kohl. Vygotsky Aprendizado e Desenvolvimento um Processo Sócio-histórico. [S. I.]: Scipione, 2006. 111 p. Disponível em: https://docs.google.com/file/d/0BwSkfHMQvCWuU2RsVTVZUFJ6MGF5VFdIXzNBdDVwRUcxd0Zj/edit. Acesso em: 15 jan. 2020.

PASSOS, Felipe; SALES, Reinaldo. Relato da resistência docente em defesa do ensino médio integrado no campus Castanhal do Instituto Federal do Pará. Terra Livre, v. 2, n. 53, p. 164-192, jul.-dez./2019. 
ROESLER, Jucimara. Comunicação, sociabilidade e educação on-line. 2008. Tese (Doutoral em Comunicação Social) - PUC RS, Porto Alegre, 2008.

SILVA, João Carlos. Uso de gamificação como instrumento de avaliação da aprendizagem. Revista da FATEC, p. 19-31, 1 fev. 2015. E-book.

SOARES, Luiza Carla. Dispositivos móveis na educação: desafios ao uso do smartphone como ferramenta pedagógica. 90 Encontro Internacional de formação de professores, Sergipe, p. 1-12, 16 maio 2016. Ebook.

VYGOTSKY, L.S. et al., Linguagem, Desenvolvimento e Aprendizagem. São Paulo, Ícone, Ed. Universidade de São Paulo, 1988.

UNESCO. Diretrizes de políticas da UNESCO para a aprendizagem móvel. Publicado pela Organização das Nações Unidas para a Educação, a Ciência e a Cultura. Paris 07 SP, France, v. 1, n. 1, fevereiro, 2013. Disponível em: < https://unesdoc. unesco.org/ark:/48223/pf0000219641?posInSet=19\&queryId=6eb29274-876a-4e55aed7-67e003bdce3e >. Acesso em: 25 mar. 2020.

ZICHERMANN, Gabe; CUNNINGHAM, Christopher. Gamification by Design: Implementing Game Mechanics in Web and Mobile Apps. Canada: O'Reilly Media, Inc, 2011. E-book.

Recebido em julho de 2020.

Aprovado para publicação em maio de 2020.

Felipe Gustavo Vieira de Almeida

Licenciatura em Informática. Instituto Federal do Pará, Brasil, felipegustavotheboss@gmail.com.

\section{Wellington Blender Palheta Silva}

Licenciatura em Informática. Instituto Federal do Pará, Brasil, wellington.blenderw98@gmail.com.

\section{Caren vanessa Pinheiro Castro}

Especialista em Engenharia em Processamento de Softwares. Instituto Federal do Pará, Brasil, vanessapinheiroc@gmail.com.

\section{Reinaldo Eduardo da Silva Sales}

Sociólogo. Mestre em Educação. Instituto Federal do Pará, Brasil, reinaldo.eduardo@ifpa.,edu.br. 